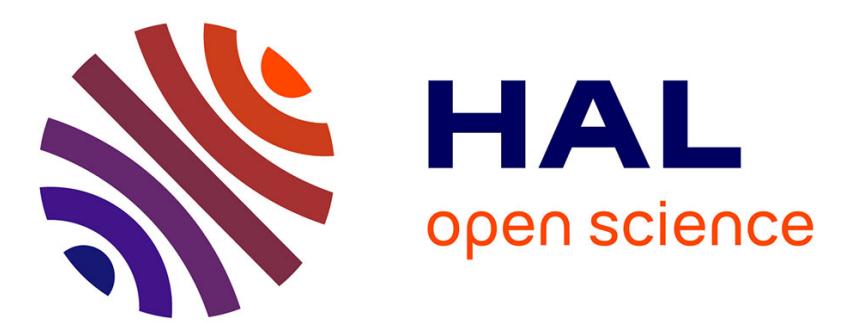

\title{
French validation of a new version of the Driver Behavior Questionnaire (DBQ) for drivers of all ages and level of experiences
}

Ludivine Gueho, Marie-Axelle Granié, Jean-Claude Abric

\section{- To cite this version:}

Ludivine Gueho, Marie-Axelle Granié, Jean-Claude Abric. French validation of a new version of the Driver Behavior Questionnaire (DBQ) for drivers of all ages and level of experiences. Accident Analysis \& Prevention, 2014, 63 (2), pp. 41-48. 10.1016/j.aap.2013.10.024 . hal-01010552

\section{HAL Id: hal-01010552 https://hal.science/hal-01010552}

Submitted on 20 Jun 2014

HAL is a multi-disciplinary open access archive for the deposit and dissemination of scientific research documents, whether they are published or not. The documents may come from teaching and research institutions in France or abroad, or from public or private research centers.
L'archive ouverte pluridisciplinaire HAL, est destinée au dépôt et à la diffusion de documents scientifiques de niveau recherche, publiés ou non, émanant des établissements d'enseignement et de recherche français ou étrangers, des laboratoires publics ou privés. 
Running head: French validation of a new version of the DBQ for drivers of all ages and level of experiences

French validation of a new version of the Driver Behavior Questionnaire (DBQ) for drivers of all ages and level of experiences

Ludivine Guého*

IFSTTAR-LMA

Chemin de la Croix Blanche, 13300 Salon de Provence, France

ludivine.gueho@ifsttar.fr

tel: +33 905686 21; fax: +33 4905686 18)

Marie-Axelle Granié

IFSTTAR-LMA

Chemin de la Croix Blanche, 13300 Salon de Provence, France

$\underline{\text { marie-axelle.granie@ifsttar.fr }}$

Jean-Claude Abric

Aix-Marseille University, 13621 Aix-en-Provence, France 
* Corresponding author

French validation of a new version of the Driver Behavior Questionnaire (DBQ) for drivers of all ages and all level of experiences

\begin{abstract}
The purpose of this study was to validate a new version of the Driver Behavior Questionnaire (DBQ) on a sample of French drivers in order to gain a better understanding of different driver behaviors, by differentiating two types of violations (aggressive and ordinary), three types of errors (dangerous, inattention and inexperience) and by taking positive behaviors into account. 525 drivers ( 205 men and 320 women), between 18 and 79 years of age, filled in a questionnaire on line including the 41 items in the new version of the DBQ and information relative to their mobility and their accident history. Exploratory factor analysis confirmed a six-factor structure: “dangerous errors", "inattention errors", "inexperience errors", "ordinary violations", "aggressive violations" and "positive behaviors". The new version of the DBQ had questionable to acceptable internal reliability. A revised version with 23 items of the new version of the DBQ was produced by selecting the items that loaded most strongly on the six factors. The results also showed the link between demographic variables (age and gender), mobility (kilometers driven weekly), the DBQ scores and the involvement in an accident in the previous five years. This study permitted to validate a more detailed version of the "Driving Behavior Questionnaire" among French drivers of all age and all level of experience.
\end{abstract}

Keywords: Driver behavior, Violations, Errors, Positive driver behaviors, Accidents 
French validation of a new version of the Driver Behavior Questionnaire (DBQ) for drivers of all ages and all level of experiences

\section{Introduction}

Human action is a decisive factor (a sole or a contributory factor) in 90 to $95 \%$ of all cases of traffic crashes (Rumar, 1985). Understanding the psychological mechanisms underlying the driver's behavior is then a major road safety challenge.

For Reason et al. (1990), understanding the different accident factors entails having a detailed classification of the different individuals' aberrant behaviors. According to them (Reason et al., 1990), unsafe behaviors can be divided into two behavior categories: violations and errors. Violations refer to deliberate deviations from practices believed necessary to maintain the safe operation of a potentially hazardous system, that is, deliberate transgressions of social codes or legal rules. They have a motivational component and are a social phenomenon that can only be understood in context (Reason et al., 1990). Errors are the result of a deficiency in processing information and are related to the individual's cognitive functions. They refer to the failure of planned actions to achieve their intended consequences and concern failures in intent, ill-suited to the situation (Reason et al., 1990). On the other side, slips and lapses are defined as involuntary deviations in the action, ill-suited to the original intent. Slips refer to attention failures, whereas lapses more refer to memory failures. While violations and errors refer to types of behavior that are potentially dangerous for oneself and for others, slips and lapses refer to behaviors that are slightly dangerous and only have consequences for the person who produces them. Violations can notably be distinguished from errors by the intentional or unintentional character of the behavior in question (Parker et al., 1995a): if the difference between the action and the socially constructed practices is voluntary, action will be defined as a transgression. If the difference is not intentional, action will be classified as an 
error. Errors and violations have different psychosocial origins and consequently entail different forms of action to rectify them. While errors can thus notably be corrected with better information, this is not the case for transgressions, for which attitudes have to be changed (Parker et al., 1995a; Reason et al., 1990).

Reason and his colleagues have developed a tool to measure and to better understand these different behaviors among the drivers: the Driver Behavior Questionnaire (DBQ) (Reason et $a l ., 1990)$. It is widely used today to gather ill-suited driver behaviors ("violations", "errors" and "slips and lapses") declared by individuals. The subjects are asked to indicate the frequency with which they experience each of the 50 items proposed, each item corresponding to one of the 3 behavior categories. Violations refer to behaviors such as "close following, speeding, risky overtaking". Errors refer to behaviors such as "failing to notice pedestrians crossing, misjudging the speed of another vehicle when overtaking”. Lastly, slips and lapses refer to behaviors such as "forgetting where one's car is parked".

The DBQ is a valid, robust tool for understanding various types of aberrant driver behaviors (De Winter and Dodou, 2010). This tool has been translated and validated in many countries, including France, for elderly drivers (Gabaude et al., 2010) using the translated version by Blockey et al. (1995). Most studies agree on the principal distinction between errors and transgressions. This structure, practically identical in different countries and with different samples (Aberg and Rimmö, 1998; Blockey and Hartley, 1995; Lajunen et al., 2004; Parker et al., 2000; Sullman et al., 2004; Xie and Parker, 2002), confirms the original structure by Reason et al., (1990) and reinforces the tool's validity. Originally using 50 items (Blockey and Hartley, 1995; Reason et al., 1990), the 27-item version (Lawton et al., 1997b; Parker et $a l ., 1995 \mathrm{a})$ is the most commonly used today. Test-retest validity testing carried out on the short version attests to the reliability of the short version of the tool. A cross-cultural study carried out on Finnish, Dutch and English samples using the version from Lawton et al. 
(1997b) and Parker et al. (1998) once again demonstrated the robustness of the DBQ's structure, thus confirming again the distinction between two second-order factors transgression and errors - in the different samples studied by Lajunen et al. (2004).

The three different behavioral categories originally used by Reason et al. (1990) have been refined in following studies. Lawton et al. (1997b), using the short version of the DBQ by Parker et al. (Parker et al., 1995a), observe two types of violations in the sample of young drivers. Ordinary violations are defined as deliberate deviations in driving but without any aggressive purpose. They notably concern violations related to speed and violations related to “maintaining progress" (Lawton et al., 1997a). These violations, guided by practical considerations such as the desire to save time, are considered as instrumental. Aggressive violations concern the violation of generally accepted social norms of driving and refer to behaviors of aggressive interpersonal violence (e.g., aggressive or hostile behaviors towards other users). These violations have an affective character and are more emotional. Äberg and Rimmo (1998) distinguish between three types of errors in a wide sample of the general population: dangerous errors corresponding to Reason's errors (1990), errors due to inattention and errors due to inexperience, the last two correspond to the "slips and lapses" identified by Reason et al. (1990). As the score for inattention errors increase with age, it seems that this kind of errors are caused by the automation of driving habits (Aberg and Rimmö, 1998). Furthermore, based on the idea that the aberrant behaviors measured by the DBQ (errors and violations) are not the only behaviors that drivers use in their everyday lives, Özkan and Lajunen (2005a) look into positive driver behaviors by adding 14 items to the original DBQ. These behaviors, governed by the intention to pay attention to traffic and to other users, can sometimes lead to errors and violations (e.g., crossing the center line so as not to splash a pedestrian with water). 
Interindividual differences in the DBQ scores could be found according to gender, age or annual mileage. Thus, men, young people and those who drive a lot commit more violations (Parker et al., 1995a; Reason et al., 1990) whereas women commit more "slips and lapses" than men (Reason et al., 1990). Furthermore, studies that have used the DBQ show that violation score is a greater predictor of active and passive accidents (De Winter and Dodou, 2010; Parker et al., 1995a), while among the elderly, accidents are predicted by the error score (active accidents) and "slips and lapses" score (passive accidents) (De Winter and Dodou, 2010; Parker et al., 2000).

All these latest research on the DBQ questionnaire (Aberg and Rimmö, 1998; Lawton et al., 1997b; Özkan and Lajunen, 2005a) provide a deeper understanding of these behaviors and of the factors explaining the different kind of aberrant behaviors. In order to explain individual differences in the risk of road accident in France and to understand more precisely the aberrant driving behaviors, it would be useful to be able to measure and to explore these different types of violations and errors. However, to the best of our knowledge, no validation among French drivers of all age and level of experiences of the latest versions of DBQ has been published, while Gabaude et al. (2010) have validated the original version by Reason et al. (1990) on a French sample of elderly people. Based on the latest versions of the DBQ validated by Lawton et al. (1997b), Äberg and Rimmo (1998) and Özkan and Lajunen (2005a), the goal of this study was then to validate a new version of the DBQ on a wide French sample of drivers to provide a better understanding of driving behaviors among French drivers of all ages and levels of experience by differentiating ordinary violations from aggressive violations, dangerous errors from inattention and inexperience errors and by measuring "positive" driving behaviors.

\section{Method}




\subsection{Materials}

Using the conceptual framework of the DBQ (Reason et al., 1990), a new version of the DBQ has been produced with 41 items based on the existing validated versions of the DBQ, including scales of violations (ordinary and aggressive) (Lawton et al., 1997b), scales of errors (Aberg and Rimmö, 1998) and positive driver behaviors toward other users (Özkan and Lajunen, 2005a). The items with the greatest factor loading on the corresponding axes in the aforementioned studies were selected for setting up the scale. Thus, the 41 items in the Likert scale selected in this way differentiated between 6 types of driver behaviors. Twelve items referred to violation behaviors, defined as a deviation from the legal rules of driver behavior and selected from the items with the greatest loading on the ordinary and aggressive violations axes in the study by Lawton et al. (1997b). Six items corresponded to ordinary violations, defined as deliberate driving deviations without any aggressive purpose (e.g., "you ignore the speed limit on the motorway"), while the other 6 items corresponded to aggressive violations, defined as conflict behaviors with other users (e.g., "You stay in a lane that you know is closed further on and you wait until the last minute to force your way into the other lane"). Nineteen items correspond to errors and were selected from among the items with the greatest loading on each of the "dangerous errors", "inattention" and "inexperience" axes for Äberg and Rimmo (1998). A differentiation was thus made among 7 dangerous error items, defined as making decisions that put the driver in danger, but without breaking the law (e.g., "while making a left-hand turn, you misjudge the distance between you and the oncoming vehicle, requiring the other vehicle to hit the brakes"), 6 inattention error items, defined as illsuited behavior due to a lack of concentration on the driving task (e.g., "you misread the signs and you get lost") and, lastly, 6 inexperience errors items, defined as ill-suited behavior due here to a lack of driving experience (e.g., "you forget what gear you are in and have to check by hand"). The 10 remaining items were selected from among the items with the greatest 
loading on the "positive behaviors" axis from Özkan and Lajunen (2005a). They corresponded to behaviors that appease social interactions (e.g., "you avoid splashing pedestrians or other users when you come upon a puddle").

For all the items, including those in common with the French version validated among older drivers by Gabaude et al. (2010), two translations from the original English wording have been made: the first by the authors and the second by a native English translator. Both of the translated formulations of each item have been compared with one another and with the previous French wording from Gabaude et al. (2010) when available. The criteria were 1/ coherence with the goal of the original questionnaires 2/ clarity of the item in French language and 3 / understanding of the item by the drivers of all ages. In order to validate the items selected further to these criteria, some pretests of the tool have been conducted among a small sample of drivers. As a result, 9 of the 41 items are shared with the previous validated French version of the DBQ (Gabaude et al., 2010): 3 items (2 inattention errors and 1 inexperience error) are formulated in the same way in both versions whereas formulation has been changed for 6 items (two dangerous errors, two ordinary violations and two aggressive violations). For each item, the participants are asked to indicate how often they have the behaviors described, on a six-point scale (ranging from " $1=$ never" to " $6=$ nearly all the time"). Along with applying the new version of the DBQ, information was gathered concerning the subjects' gender, age, the number of years holding a driver's license, motor vehicle ownership and use, kilometers traveled per week as the driver of a motor vehicle (from $0 \mathrm{~km}$ to more than $350 \mathrm{~km}$ per week) and their accident history over the past 5 years.

\subsection{Participants}

In order to obtain the widest and most diversified sample possible in terms of age, socioprofessional categories and geographical location, it has been decided to proceed using a web- 
based data collection. In France, $63 \%$ of households have internet access at home and $41 \%$ of persons aged 55-64 years use internet daily (75\% in the 16-24 age group) (Deroin, 2010). The means of dissemination included the electronic mails, some social networking websites and Internet forums, and snow ball sampling. The participants answered the questionnaire individually, after their informed consent had been obtained. The responses were totally anonymous, as the individuals were only identified by the day and time of completion of the questionnaire.

Only results from participants living in France and having a category B driver's license (European driving license for motor vehicles with a mass $<3500 \mathrm{~kg}$ ) were kept. The sample comprised 525 participants (205 men and 320 women), between 18 and 79 years of age (mean $=30.39$ years, $\mathrm{SD}=10.92$ ). The participants were separated into 5 age groups (see Table 1 ). The distribution of participants of either gender was equivalent within each age group $\left(\chi^{2}(6)=\right.$ 12.25, ns). The sample comprised students (33.90\%), managerial-level employees and senior intellectual workers (32.19\%), salaried employees and manual laborers (26.29\%), and, to a lesser extent, retirees (3.62\%) and unemployed people (4\%). All individuals had a license B with a range of 0-52 years of driving experience (mean 11.04, $\mathrm{SD}=10.47$ ) and half the sample $(53.14 \%)$ with less than 8 years of driving experience. In all, $11 \%$ of the sample had both a license B and a license A (European rider license for motorcycles of all sizes). More than $87 \%$ of the sample owned a motor vehicle and, in $86.3 \%$ of cases, it was a light vehicle. Concerning driving frequency, half of the sample (53.71\%) declared that they drive every day, $17.7 \%$ stated that they drive four or five times a week, $25 \%$ stated that they drive one to three time a week, and just $3.6 \%$ of the participants said that they never drive. Lastly, $22.9 \%$ of the sample drove a car less than $50 \mathrm{~km}$ a week and $30.48 \%$ drove 50 to $150 \mathrm{~km}$. The weekly mileage of the studied sample is representative of drivers in France (Armoogum et al., 2010). Finally, the number of accidents in the last 5 years ranged from $0(68.4 \%)$ to more 
than $3(2.3 \%)$, with $23.4 \%$ of the sample had one accident and $5.9 \%$ had two accidents in the last 5 years.

\section{Results}

Table 2 shows the means and standard deviations for each of the 41 items in the new version of the DBQ. The most frequently reported behavior concerns taking other users' movement into account (item 31: "When parking, you take other road users into account so as not hinder their free movement"). This is followed by other positive behaviors. Thus, the most commonly reported items are the most desirable from the point of view of safety and interpersonal relations with other users. On the other hand, the least frequently reported behaviors were violations and errors.

\subsection{Tool validation}

In order to explore the factorial structure of the DBQ, principal component analysis with orthogonal Varimax rotation was carried out on all 41 items in the scale. The scree plot indicated that the data best fit a six-factor solution, which accounted for $39.94 \%$ of the total variance. Six axes with eigenvalues $>1$ were identified. A cut-off point of .39 was used for item loading values. Items with loading values $>.39$ on two factorial axes or more were excluded. All the results are presented in table 2.

The first axis, "inattention errors", explained $13.69 \%$ of the variance. It was defined by 7 items: 5 related to inattention errors and 2 to inexperience errors. Items loading on this axis all had in common the unintentional character of the slightly dangerous behaviors that appeared to be due to a lack of attention by the individual (item 24 - "You misread the signs and you get lost"). Behaviors loading on the first axis measured lapses, according to the classification 
of aberrant behaviors by Reason et al. (1990), or inattention errors, according to the classification by Äberg and Rimmo (1998).

The second axis, "ordinary violations" explained $8.33 \%$ of the variance and was determined by 6 items: 4 items related to ordinary violations, one item related to aggressive violations and one item related to dangerous errors. Items loading on this axis were characterized by the deliberate transgression of traffic regulations, but without any aggressive purpose (item 37 "You ignore the speed limit on the motorway").

The third axis, "positive behaviors", explained $6.34 \%$ of the variance, with 9 items corresponding to positive behaviors. All items loading on this axis involved pro-social behaviors intended to facilitate interactions with other users, whether drivers (item 39 - "You do everything you can not to become an obstacle for other drivers") or pedestrians (item $11-$ "You avoid splashing pedestrians or other users when you come upon a puddle").

The fourth axis, "aggressive violations", was determined by 3 items of aggressive behaviors aimed at other drivers loading negatively on the factor. These items were characterized by the deliberate transgression of generally accepted driving standards (item 12 - "You get angry with another driver and follow him to let him know what you think of him"). An item related to positive behaviors (item 29) with positive loading value $>.39$ both on this axis and on the third axis was excluded. It explained $4.47 \%$ of the variance.

The fifth axis, "dangerous errors", explained $3.86 \%$ of the variance, with 6 dangerous error items. These items all had in common the unintentional character of the dangerous behavior (item 8 - "While making a left-hand turn, you misjudge the distance between you and the oncoming vehicle, requiring the other vehicle to hit the brakes").

The sixth and last axis, "inexperience errors", included 4 inexperience error items and explained $3.24 \%$ of the variance. These items were characterized by the unintentional character of the slightly dangerous behavior that appeared to be caused by the individual's 
lack of driving experience (item 1 - "You realize you are driving in $4^{\text {th }}$ although you are going fast enough to be in $\left.5^{\text {thy }}\right)$.

After eliminating the 6 problematic items, the 35 items on the driver behavior scale could be distributed, after another PCA with Varimax rotation, into 6 axes explaining $42.83 \%$ of the variance. Cronbach's alphas have been calculated for each scale and ranged from questionable, for "ordinary violations" $(\alpha=.64)$, "inattention errors" $(\alpha=.67)$, "inexperience errors" $(\alpha=.65)$ and "dangerous errors" $(\alpha=.69)$, to acceptable for "positive behaviors" $(\alpha$ $=.70)$ and "aggressive violations" $(\alpha=.72)$.

\subsection{Refining the scale}

The main objective of the study was to develop a reliable self-reporting instrument for measuring drivers' risky behaviors leading to accidents. The 35-item version may not be practical for use in future self-reporting studies because, when used with other self-reporting measures, it can lead to questionnaires that are too long in terms of completion time. A shorter version that is capable of reliably measuring the factor structure reported above would be more practical to use. For this, the 4 items in each of the 6 dimensions involved (dangerous errors, inattention errors, inexperience errors, ordinary violations, aggressive violations and positive behaviors) with the highest loading on each of the 6 factors were selected, except for the aggressive violations dimension, which only had three items in the 35 -item version. These 23 items then underwent another PCA with Varimax rotation. The items only loaded on one axis (i.e. loading <.40 on the other axes) and all the items have the strongest loading on the expected axis. After rotation, the six factors explained $52.5 \%$ of the variance.

The version used for the rest of the analysis was the short version of the driver behavior questionnaire, comprising 23 items. The total scores for dangerous errors, inattention errors, 
inexperience errors, aggressive violations, ordinary violations and positive behaviors were calculated and used as composite scales in the following analyses.

\subsection{Multiple correlation coefficients}

Pearson's r Correlations between the 6 new scores of the short French version of the DBQ were calculated to examine the relationships between the types of behaviors differentiated by the DBQ. Positive behaviors were negatively correlated with inattention and inexperience errors, ordinary and aggressive violations. The 3 scales of errors were positively intercorrelated so as the 2 scales of violations. The ordinary and aggressive violations were positively correlated with dangerous errors and ordinary violations were positively correlated with inattention errors. Nevertheless, correlation coefficients are weak. Thus, scales are linked but provide different information and can been considered as distinct scales.

\subsection{Variables associated with DBQ factor scores}

In order to compare the new French version of DBQ with previous studies (Parker et al., 1995a; Reason et al., 1990), scores on each of the six new DBQ factors were regressed on demographic variables, namely age (in years), gender $(1=$ male, $2=$ female $)$ and weekly mileage. Standardized regression coefficients and significance levels are shown in table 4. Multiple regression model was not significant for dangerous errors. Inattention error score was associated with gender and weekly mileage. Both variables accounted for $6.2 \%$ of the variance in the inattention error score. The reported inattention errors were associated with femaleness and lower weekly mileage. Inexperience error score was significantly predicted by 
respondent's age, gender and weekly mileage. Together, these three variables accounted for $7.3 \%$ of the total variance in the inexperience error score. The reported inexperience errors were associated with femaleness, youth and lower weekly mileage. Ordinary violations were significantly predicted by gender, age and weekly mileage. The three variables explained $9.2 \%$ of the total variance in the ordinary violation score. The reported commission of ordinary violations was associated with maleness, youth and a higher weekly mileage. Aggressive violations were only significantly predicted by higher weekly mileage, this variable accounting for $4.9 \%$ of the total variance in aggressive violation score. Lastly, positive behaviors were only significantly predicted by age, with positive behavior score increasing as age increased, this factor accounting for $3.9 \%$ of the total variance in the positive behavior score.

\subsection{Variables associated with the accident involvement}

As crashes generally have a Poisson distribution, the number of crashes has been transformed into a dichotomous variable and a logistic regression analysis was performed with crashes (with $0=$ no crash in the previous 5 years and $1=$ at least one crash) as the dependent variable and gender, age, weekly mileage and the 6 DBQ scores as predictor variables. A total of 525 cases were analyzed and the full model was significantly reliable (chi-square $=46.79, \mathrm{df}=9$, $\mathrm{p}<.0001, \mathrm{p}=.894$ to the Hosmer-Lemeshow test). This model account between $8.5 \%$ and $12 \%$ of the variance in crashes, with $92.8 \%$ of the participants without crash successfully predicted. However, only $16.3 \%$ of the predictions for group with at least one crash were accurate. Overall, $68.6 \%$ of predictions were accurate. The final model included age (OR = $.956)$, weekly mileage $(\mathrm{OR}=1.255)$, score of dangerous errors $(\mathrm{OR}=1.09)$, inattention errors $(\mathrm{OR}=1.076)$ and inexperience errors $(\mathrm{OR}=.931)$. Having at least a crash in the last 5 years 
is associated with lower age, lower inexperience error score and higher scores for dangerous errors, inattention errors and higher weekly mileage. Gender and the other DBQ scores were not significant contributors to the final regression model.

\section{General discussion}

\subsection{Validating a questionnaire}

The purpose of this study was to validate a new version of the Driver Behavior Questionnaire on a French sample in order to understand more precisely the aberrant driving behaviors by differentiating between different types of driving behaviors. These driving behaviors included violation behaviors (aggressive and ordinary) and errors (dangerous errors and errors with less serious consequences which may be due to inattention or inexperience) among behaviors with an accident risk, and also positive behaviors toward other road users.

This study validates the DBQ scales with a French sample and provides differentiation between different types of driving behaviors. A reliable scale of self-reported behaviors providing a useful classification of driving behavior was developed based on different existing versions of DBQ. From the original 41 items, an instrument with 35 items and a short version with 23 items were produced. Both revealed a 6-factor structure that is easy to interpret (ordinary violations, aggressive violations, dangerous errors, errors inattention, inexperience errors and positive behaviors), with internal reliabilities ranging from questionable to acceptable.

The results thus appear to confirm the aberrant behavior classification produced by Reason $e t$ al. (1990) for driver behaviors and showed a distinction between transgressions and errors, as demonstrated by Reason et al.(1990) and observed in most studies (Aberg and Rimmö, 1998; Blockey and Hartley, 1995; Lajunen et al., 2004; Parker et al., 2000; Parker et al., 1995a; 
Parker et al., 1995b; Xie and Parker, 2002), notably for a French sample of elderly people (Gabaude et al., 2010; Obriot-Claudel and Gabaude, 2004). Violations (ordinary and aggressive) are distinguished from other types of behavior with accident risks, i.e., errors (dangerous, inattention and inexperience). These two types of behavior are distinguished by their intentionality. Violations ("transgressions" for Reason et al., 1990), that is deliberate transgressions of social codes or rules, refer to intentional behaviors with a motivational component. On the other hand, errors, which correspond to a failure of planned actions to achieve their goal, refer to unintentional difference between the action and the socially constructed behaviors.

Based on the work by Lawton et al. (1997b), two types of violation are differentiated in the present study. In keeping with what is observed with the English, Finnish and Dutch samples (Lajunen et al., 2004; Lawton et al., 1997a; Özkan et al., 2006), the structure obtained in this French sample, with an average age being 30 years of age, shows two violation axes: ordinary violations and aggressive violations, which replicate those obtained by Lawton et al. (1997a) on a relatively young sample (17-40 years of age). However, on a wider sample in terms of age, Lawton et al. (1997b) found that, next to the aggressive violation axis, the ordinary violation behaviors were distributed into two axes: "fast driving" and "maintaining progress" behaviors. This second distinction is not found in the present study. Collecting data on a larger and older French sample would thus be interesting in order to verify whether ordinary violations are differentiated in terms of their relation to speed and maintaining progress on older drivers.

The present study also aims to differentiate between different types of errors. The three axes obtained confirm those found by Äberg and Rimmo (1998): dangerous errors, inattention errors and inexperience errors. They group together items corresponding both to errors and to lapses according to the classification made by Reason et al. (1990). Certain items in the errors 
group however load onto two or three error axes at the same time, which shows that the distinction between the three types of errors is not always obvious and these three axes group together items that all referred to the same general category of errors (Reason et al., 1990). Distinguishing between the different kinds of errors is of interest in that it provides a more detailed understanding of individuals' behaviors. Thus, for example, depending on their age or gender, individuals may have behaviors related to different types of errors.

Lastly, different items load on the positive behaviors axis, related to pro-social behaviors designed to facilitate interactions with other users, whether drivers or pedestrians. As road behaviors are not limited to the aberrant behaviors measured by the DBQ, these behaviors have to be taken into account (Özkan and Lajunen, 2005a). This study thus validates the positive behavior questionnaire proposed by Özkan and Lajunen (2005a) on a French sample.

\subsection{Relationships between demographic and mobility variables, DBQ scores and crashes}

The results shows that femaleness is associated with inattention and inexperience errors, which is in line with the results of many studies that have shown a greater propensity among women to declare more lapses (Özkan and Lajunen, 2006; Parker et al., 1995a; Reason et al., 1990) and inexperience errors (Äberg and Rimmo (1998). The greater propensity among men to commit dangerous errors found by Äberg and Rimmo (1998) is not found in the present study, however. The studies nonetheless show rather contradictory results in terms of the link between gender and error behaviors (Blockey and Hartley, 1995; Özkan and Lajunen, 2005b; Özkan and Lajunen, 2006; Parker et al., 1995a; Reason et al., 1990). The results also show that male drivers declare more ordinary violations. This result is in keeping with the results found in the literature showing a greater propensity among men to declare more road transgressions than women, at all ages (Aberg and Rimmö, 1998; Blockey and Hartley, 1995; Harré et al., 1996; Obriot-Claudel and Gabaude, 2004; Özkan and Lajunen, 2005b; Özkan and 
Lajunen, 2006; Parker et al., 1995a; Simon and Corbett, 1996; de Winter and Dodou, 2010). More precisely, the results of the present study shows gender differences in ordinary violations, but not in aggressive violations, which were found in others studies (Lawton et al., 1997b; Özkan and Lajunen, 2006). This shows the importance of making a distinction between these two types of violations.

In keeping with the literature, results concerning age show that younger drivers commit more violations (Aberg and Rimmö, 1998; Blockey and Hartley, 1995 ; Obriot-Claudel and Gabaude, 2004; Özkan and Lajunen, 2005a; Özkan et al., 2006; Parker et al., 2000; Parker et al., 1995a; Rimmö and Hakamies-Blomqvist, 2002; de Winter and Dodou, 2010) and more precisely, declare more ordinary violations than older individuals (Özkan et al., 2006). The results also show that the number of inexperience errors drops with age: as younger drivers had less driving experience, they are more likely to commit inexperience errors than more experienced drivers (De Winter and Dodou, 2010). Äberg and Rimmo (1998), however, did not find this association between age and inexperience errors, which could be explained by the difference in the learning driving conditions between France and Sweden. Lastly, in keeping with the results from Özkan and Lajunen (2005a), the results show that age is positively connected to positive behaviors, which can be explained by the focusing of young drivers' attention to the traffic situation because of their driving inexperience.

In keeping with previous studies (Äberg and Rimmo, 1998 ; Blockey and Hartley, 1995; Gabaude et al., 2010; Özkan and Lajunen, 2005a ; Parker et al., 1995a), the results show a link between heavy driving activity, lower scores for inattention and inexperience errors and higher scores for ordinary and aggressive violations. These relationships may be explained by the greater driving experience benefiting drivers who drive over greater distances. Thus, the longer the distances, the more one acquires a certain degree of experience that reduces the risk 
of committing inattention and inexperience errors but increase the likelihood of violating traffic regulations (ordinary violations) or social rules (aggressive violations).

The results show that having at least one crash in the last 5 years is associated with lower age, higher weekly mileage, lower inexperience error score and higher scores for dangerous errors and inattention errors. The link between higher driving activity, lower inexperience error scores and involvement in at least one accident can be explained by exposure, as the results also show the link between higher weekly mileage and lower inexperience error scores. The connection between errors and past accidents has been observed in a meta-analysis by de Winter and Dodou (2010) and the results obtained on the relation between inattention errors and crashes are in line with previous studies (Parker et al. (Parker et al., 2000; Roca et al., 2013). These results must be treated with caution however, as the DBQ scores explain only a very small portion (between $8.5 \%$ and $12 \%$ ) of the variance of crashes. Nevertheless, as the main goal of the study was to better understand the variables that explain driving behaviors, these results are nonetheless quite interesting and may provide a better understanding of individual differences in the risk of road accident in France even if the effects of other variables need to be explored.

\section{Limitations of the study}

While this study provided a French enriched version of the DBQ, there are some limitations that may moderate the generalizability of the findings and that have to be taken into account in planning future research. First, we recruited a large and diverse sample in terms of age and geographical location through a web-based survey. Nevertheless, the sample is mostly from middle and upper socioprofessional categories, with over $60 \%$ of students, employees of managerial-level, or senior intellectual workers, which is not representative of French population (INSEE, 2011). Hence, the results may not be applied to drivers issued from 
socioprofessional categories more disadvantaged. Besides, the results may not be applied to all the older drivers since the data collection through internet may have led to recruit older adults who are not representative of the population. So, there could be a differential effect in the recruitment of older versus younger drivers.

Second, as in the DBQ by Reason et al. (1990), the behavior classification provided by this questionnaire was based on declared behaviors and not on observed behaviors, which may have limits, notably concerning the negative impact of social desirability. Nonetheless, Lajunen and Summala (2003) have shown that the bias caused by social desirability was minimal in the answers on the DBQ. Moreover, there is a strong link between the driver behaviors declared, measured with the DBQ, and actual driver behaviors on the road (Rolls et al., 1991). Behaviors as measured by this new version of the DBQ can thus provide a good approach to risk behaviors measured more objectively.

\section{Conclusion}

The results of this study corresponded to the classification by Reason et al. (1990), with the distinction between errors and transgressions being obvious. Furthermore, taking into account the studies that differentiate several types of violations and errors and positive behaviors, this validation study led to a six-factor structure that enabled to differentiate between dangerous errors, inattention errors, inexperience errors, ordinary violations, aggressive violations and, lastly, positive behaviors that are rarely measured in driver behavior studies.

This new version of the DBQ provided a more completed categorization of aberrant driving behaviors and of positive driving behaviors. This tool may be useful for all researchers which want to investigate the behaviors of French drivers, whatever their age and their level of driving experience. It will be possible to gain a more detailed understanding of driver behaviors and of the related psychological and mobility factors. Validated on a wide French 
sample, this tool may prove to be useful in measuring and analyzing differences in the frequency of these behaviors, notably as a function of gender and age, thus making it possible to implement prevention campaigns adapted to the intended audience.

\section{Acknowledgements}

We would like thank the participants for their participation and the reviewers for their very constructive comments.

\section{References}

Aberg, L., Rimmö, P.-A., 1998. Dimensions of aberrant driver behaviour. Ergonomics 41, 3956.

Armoogum, J., Hubert, J.-P., Roux, S., Jeannic, T.L., 2010. Plus de voyages, plus de kilomètres quotidiens : une tendance à l'homogénéisation des comportements de mobilité des Français, sauf entre ville et campagne. La Revue du CGDD, numéro spécial "La Mobilité des Français, panorama issu de l'Enquête Nationale Transports et Déplacements 2008", 5-24.

Blockey, P.N., Hartley, L.R., 1995. Aberrant driving behaviour: errors and violations. Ergonomics 38 (9), 1759-1771.

De Winter, J.C.F., Dodou, D., 2010. The Driver Behavior Questionnaire as a predictor of accidents: A meta-analysis. Journal of Safety Research.

Deroin, V., 2010. Diffusion et utilisation des TIC en France et en Europe en 2009. DEPS Culture chiffres 2 (2), 1-12.

Gabaude, C., Marquié, J.-C., Obriot-Claudel, F., 2010. Self-regulatory driving behaviour in the elderly: relationships with aberrant driving behaviours and perceived abilities. Le Travail Humain 73 (1), 31-52. 
Harré, N., Field, J., Kirkwood, B., 1996. Gender differences and areas of common concern in the driving behaviors and attitudes of adolescents. Journal of Safety Research 27 (3), 163-173.

INSEE, 2011. France, portrait social - édition 2011. Fiches - Travail, emploi. INSEE Références, Paris.

Lajunen, T., Parker, D., Summala, H., 2004. The Manchester Driver Behaviour Questionnaire: a cross-cultural study. Accident Analysis \& Prevention 36 (2), 231238.

Lajunen, T.J., Summala, H., 2003 Can we trust self-reports of driving? Effects of impression management on driver behaviour questionnaire responses. Transportation Research. Part F: Traffic Psychology and Behaviour 6, 97-107.

Lawton, R., Parker, D., Manstead, A.S.R., Stradling, S.G., 1997a. The role of affect in predicting social behaviours: The case of road traffic violations. Journal of Applied Social Psychology 27, 1258-1276.

Lawton, R., Parker, D., Stradling, S.G., Manstead, A.S.R., 1997b. Predicting road traffic accidents: The role of social deviance and violations. British Journal of Psychology 88 (2), 249-262.

Obriot-Claudel, F., Gabaude, C., 2004. The Driver Behaviour Questionnaire: A French study applied to elderly drivers. In: Proceedings of the ICTTP' 2004, Nottigham, UK.

Özkan, T., Lajunen, T., 2005a. A new addition to DBQ: Positive Driver Behaviours Scale. Transportation Research Part F: Traffic Psychology and Behaviour 8 (4-5), 355-368.

Özkan, T., Lajunen, T., 2005b. Why are there sex differences in risky driving? The relationship between sex and gender-role on aggressive driving, traffic offences, and accident involvement among young turkish drivers. Aggresive Behavior 31 (6), 547558. 
Özkan, T., Lajunen, T., 2006. What causes the differences in driving between young men and women? The effects of gender roles and sex on young drivers' driving behaviour and self-assessment of skills. Transportation Research Part F: Traffic Psychology and Behaviour 9, 269-277.

Özkan, T., Lajunen, T., Summala, H., 2006. Driver Behaviour Questionnaire: A follow-up study. Accident Analysis \& Prevention 38 (2), 386-395.

Parker, D., Lajunen, T., Stradling, S., 1998. Attitudinal predictors of interpersonally aggressive violations on the road. Transportation Research Part F: Traffic Psychology and Behaviour 1 (1), 11-24.

Parker, D., McDonald, L., Rabbitt, P., Sutcliffe, P., 2000. Elderly drivers and their accidents: the Aging Driver Questionnaire. Accident Analysis \& Prevention 32 (6), 751-759.

Parker, D., Reason, J.T., Manstead, A.S.R., Stradling, S.G., 1995a. Driving errors, driving violations and accident involvement. Ergonomics 38 (5), 1036-1048.

Parker, D., West, R., Stradling, S., Manstead, A.S.R., 1995b. Behavioural characteristics and involvement in different types of traffic accident. Accident Analysis \& Prevention 27 (4), 571-581.

Reason, J.T., Manstead, A.S.R., Stradling, S., Baxter, J.S., Campbell, K., 1990. Errors and violations on the roads: a real distinction? Ergonomics 33 (10/11), 1315-1332.

Rimmö, P.A., Hakamies-Blomqvist, L., 2002. Older drivers' aberrant driving behaviour, impaired activity, and health as reasons for self-imposed driving limitations. Transportation Research Part F: Traffic Psychology and Behaviour 5 (1), 47-62.

Roca, J., Lupiáñez, J., López-Ramón, M.-F., Castro, C., 2013. Are drivers’ attentional lapses associated with the functioning of the neurocognitive attentional networks and with cognitive failure in everyday life? Transportation Research Part F: Traffic Psychology and Behaviour 17 (98-113). 
Rolls, G., Hall, R.D., Ingham, R., McDonald, M., 1991. Accident risk and behavioural patterns of younger drivers. AA Foundation for Road Safety Research, Southampton.

Rumar, K., 1985. The role of perceptual and cognitive filters in observed behaviour. Human behaviour and traffic safety, 151-170.

Simon, F., Corbett, C., 1996. Road traffic offending, stress, age, and accident history among male and female drivers. Ergonomics 39, 757-780.

Sullman, M.J.M., Meadows, M., Pajo, K., 2004. Errors, lapses and violations in the drivers of heavy vehicles. Traffic and transport psychology: theory and application: proceedings of the ICTTP 2000, 147-147.

Xie, C.-Q., Parker, D., 2002. A social psychological approach to driving violations in two Chinese cities. Transportation Research Part F: Traffic Psychology and Behaviour 5 (4), 293-308. 